\title{
Identification of Two Related Markers for Common Acute Lymphoblastic Leukemia as Heat Shock Proteins
}

\author{
John R. Strahler, ${ }^{\star}$ Rork Kuick, ${ }^{*}$ Christoph Eckerskorn, ${ }^{\ddagger}$ \\ Friedrich Lottspeich," Bruce C. Richardson," David A. Fox, "Lloyd M. Stoolman," \\ Curtis A. Hanson," Dean Nichols, " H. Jane Tueche,* and Samir M. Hanash* \\ Departments of *Pediatrics, Internal Medicine, and "Pathology, University of Michigan Medical School, Ann Arbor, Michigan 48109; \\ ${ }^{\ddagger}$ Max-Planck-Institut für Biochemie, D-8033 Martinsried, Federal Republic of Germany
}

\begin{abstract}
By direct analysis of the polypeptide constituents of leukemic cells, we have previously detected several polypeptides that are restricted in their expression to acute lymphoblastic leukemia (ALL). In this study, we provide evidence that two polypeptides designated $L 2$ and $L A$ are structurally related and represent novel markers for common ALL. Partial amino acid sequence analysis did not uncover differences between L2 and L4. The sequences obtained correspond to a previously cloned human gene designated hsp27 that is expressed, following heat shock treatment, in a variety of cells. ${ }^{32} \mathbf{P}_{\mathrm{i}}$ incorporation studies indicate that $L A$ is an unphosphorylated form and $L 2$ is a phosphorylated form of hsp27. The two forms were inducible by heat shock in leukemic and nonleukemic lymphoid cells. Thus, in acute leukemia, the common ALL subtype is uniquely characterized by the constitutive expression of a polypeptide that represents a major cellular phosphoprotein. (J Clin. Invest. 1990. 85:200-207.) acute lymphoblastic leukemia • heat shock protein • polypeptide marker
\end{abstract}

\section{Introduction}

Most evidence to date indicates that selective gene expression in acute leukemia, as reflected by cell surface marker phenotype, is primarily determined by lineage of origin and maturation status of the leukemic cells (1). In acute lymphoblastic leukemia (ALL), ${ }^{1}$ there is substantial evidence to indicate that clinical features and treatment outcome vary between immunologic subtypes (2). An improved understanding of the extent to which the various subtypes differ with respect to overall gene expression could help establish a molecular basis for the clinical variability observed in ALL.

These results were presented at the "Two-Dimensional Electrophoresis" meeting, Vienna, Austria, 8-11 November 1988, which was published in abstract form (1988. Electrophoresis. 9:629).

Address reprint requests to Dr. Strahler, R4451 Kresge I, Box 0510, University of Michigan Medical Center, Ann Arbor, MI 48109. 1989.

Received for publication 14 April 1989 and in revised form 8 August

1. Abbreviations used in this paper: $\mathrm{ALL}$, acute lymphoblastic leukemia; cALL, common acute lymphoblastic leukemia; CALLA, common acute lymphoblastic leukemia antigen; 2-D, two-dimensional; TdT, terminal deoxynucleotidyl transferase.

J. Clin. Invest.

(C) The American Society for Clinical Investigation, Inc.

0021-9738/90/01/0200/08 $\$ 2.00$

Volume 85, January 1990, 200-207
As part of an effort aimed at characterizing the polypeptide constituents of leukemic cells, we have detected 12 polypeptides that exhibit lymphoid specificity using two-dimensional polyacrylamide gel electrophoresis (2-D PAGE) (3). One cytosolic polypeptide, termed L4, was detected in leukemic cells from patients with common ALL (cALL). Quantitative analysis indicated that the amount of L4 is strongly correlated with expression of the common acute lymphoblastic leukemia antigen (CALLA) (4). In this study we provide evidence that another cytosolic polypeptide, designated L2, with a similar estimated molecular weight as L4, is also a marker for CALL. Structural studies indicate that both polypeptides are distinct from CALLA or known markers and have an amino acid sequence identical to a heat shock protein not known previously to be constitutively expressed in lymphoid cells (5).

\section{Methods}

Sources of cells for analysis. The primary source of leukemic cells was a group of 150 patients with acute leukemia studied at the time of initial diagnosis. All patients were advised of procedures and attendant risks in accordance with the institutional guidelines, and gave informed consent. The specific diagnosis was made on the basis of morphological features and histochemical staining of cells with peroxidase, esterase, and Sudan black; rosetting with sheep erythrocytes (6); and reactivity with a battery of monoclonal antibodies. Terminal deoxynucleotidyl transferase (TdT) was detected by indirect immunofluoresence (7). Leukemic cells were obtained by Ficoll-Hypaque gradient centrifugation of either heparinized peripheral blood or bone marrow. The leukemic cells constituted $85 \%$ or more of the total mononuclear cells in most preparations. Additional samples were analyzed to determine the occurrence of the $\mathrm{L} 2$ polypeptide. Samples included leukemic cells from 3 patients with B ALL, 17 patients with T ALL, 6 adults with chronic lymphocytic leukemia (B cell type), peripheral blood $\mathrm{T}$ lymphocytes and phytohemagglutinin (PHA)-stimulated $T$ lymphocytes from 13 normal individuals; peripheral blood B lymphocytes and EBV-transformed B cells from 6 nonleukemic individuals; thymus-derived lymphocyte subpopulations, $4 \mathrm{~T}$ cell clones derived from a single nonleukemic individual and 8 lymphoblastoid cell lines including three T cell, three B cell, one pre-B, one Burkitt lymphoma, all established from patients with leukemia. The 2-D gel database also included patterns for normal neutrophils, platelets, monocytes, and 20 solid tumor cell lines including neuroblastoma, melanoma, glioma, sarcoma, and colon and ovarian carcinoma.

Surface immunophenotyping. Cell samples were analyzed for reactivity with a battery of monoclonal antibodies against the following antigens: CD1 (T6), CD2 (T11), CD3 (T3), CD4 (T4), CD5 (Leu1), CD7 (Leu 9), CD8 (T8), CD10 (CALLA), CD11 (Mo1), CD13 (My7), CD14 (Mo2), CD19 (B4), CD20 (B1), CD33 (My9), CD38 (T10), and I2 (HLA D/DR) (8). The diagnosis of T ALL was excluded on the basis of lack of reactivity with specific $T$ cell markers and lack of rosetting with sheep erythrocytes. The percentage of the cell population stained with each monoclonal antibody and the mean channel of fluorescent intensity of staining (a measure of antigen density) were quantitated on a flow cytometer (Epics V, Coulter Electronics, Inc., Hialeah, FL). 
Nonspecific binding of the primary antibodies was assessed with an unrelated isotype specific mouse monoclonal antibody.

Cell culture and metabolic labeling. Four $\mathrm{T}$ cell clones established from a nonleukemic individual (9), and an EBV-transformed B lymphoblastoid cell line established from a nonleukemic individual with Bloom syndrome were cultured in RPMI 1640 supplemented with $10 \%$ fetal bovine serum, penicillin-streptomycin $(50 \mathrm{U} / \mathrm{ml}$ and 50 $\mu \mathrm{g} / \mathrm{ml}$, respectively) and glutamine $(2 \mathrm{mM})$. Cells were taken for experiments in their logarithmic growth phase. Peripheral blood lymphocytes or cryopreserved lymphoblasts from a patient with cALL were maintained in culture medium at $37^{\circ} \mathrm{C}$ for $16 \mathrm{~h}$. For heat shock, cell cultures, lymphocytes or lymphoblasts, were incubated at $42^{\circ} \mathrm{C}$ for $2 \mathrm{~h}$ and returned to $37^{\circ} \mathrm{C}$ for an additional $16 \mathrm{~h}$ and harvested. Identical flasks were continuously maintained at $37^{\circ} \mathrm{C}$ and served as controls. For the preparation of ${ }^{32} \mathrm{P}$-labeled proteins, cells $\left(5 \times 10^{6}\right)$ were incubated with $\mathrm{PO}_{4}$-free RPMI 1640 for $30 \mathrm{~min}$. $\left[{ }^{32} \mathrm{P}\right] \mathrm{H}_{3} \mathrm{PO}_{4}$ (carrier free, Amersham Corp., Arlington Heights, IL) was added at $0.25 \mathrm{mCi}$ / $\mathrm{ml}$ for $16 \mathrm{~h}$ at $37^{\circ} \mathrm{C}$. For heat-shocked cells, labeling was done immediately after heat shock.

2-D electrophoresis. Cell pellets were solubilized by addition of lysis buffer consisting of (per liter) $8 \mathrm{M}$ urea, $20 \mathrm{ml}$ of Nonidet P-40 surfactant, $20 \mathrm{ml}$ of ampholytes (pH 3.5-10), $20 \mathrm{ml}$ of 2-mercaptoethanol, and $0.2 \mathrm{mM}$ of phenylmethylsulfonyl fluoride in distilled deionized water. 2-D PAGE was done as previously described (10). In most cases $25-\mu l$ aliquots containing solubilized cells $\left(2.5 \times 10^{6}\right)$ were immediately applied onto isofocusing gels. First-dimension gels contained 50 $\mathrm{ml}$ of ampholytes per liter (pH 3.5-10). Isofocusing was done at 1,200 $\mathrm{V}$ for $16 \mathrm{~h}$ and $1,500 \mathrm{~V}$ for the last $2 \mathrm{~h}$. 20 gels were run simultaneously. For the second-dimension separation, an acrylamide gradient of $11.4-14.0 \mathrm{~g} / \mathrm{dl}$ was used. Protein spots in gels were visualized by the silver-staining technique of Merril et al. (11). Unsolubilized aliquots were frozen as pellets at $-80^{\circ} \mathrm{C}$.

Purification and structural studies of L2 and L4. Polypeptides L2 and $\mathrm{L} 4$ were isolated from cells of a patient with CALL. The relative integrated intensities of $\mathrm{L} 2$ and $\mathrm{L} 4$ were 3.40 and $4.18 \mathrm{OD} \times \mathrm{mm}^{2}$, respectively. Solubilized proteins were separated by semipreparative 2-D PAGE $\left(15 \times 10^{6}\right.$ cell equivalents per gel $)$, essentially as for analytical 2-D PAGE. After electrophoresis, gels were either rapidly stained with Coomassie Blue and destained, or protein was electroblotted from the gel onto siliconized glass fiber filters (Glassybond, Biometra, Göttingen, FRG) as previously described (12). Individual polypeptides in Coomassie Blue-stained gels were cored from the gel and the gel pieces were washed extensively with distilled deionized water, lyophilized to near dryness and stored at $-20^{\circ} \mathrm{C}$ until processed further. Siliconized glass fiber filters were stained with Coomassie blue and dried in vacuo. Protein containing spots were excised from the filter with a scalpel and stored at $-20^{\circ} \mathrm{C}$ under $\mathrm{N}_{2}$.

Amino acid sequence analysis of polypeptides L2 and L4. For $\mathrm{NH}_{2}$-terminal sequence analysis, the proteins electroblotted onto siliconized glass fiber filters were excised and applied directly to a gas phase sequencer (model 470A, Applied Biosystems, Inc., Foster City, CA) as described (12). As a control to ascertain that polypeptides L2 and $L 4$ were above the detection level of the sequencing system and that the 2-D procedure did not result in artifactual $\mathrm{NH}_{2}$-terminal blockage, a known lymphocytic protein, $\mathrm{HuCha} 60$, with an open $\mathrm{NH}_{2}$ terminus (13) was excised from the same filters from which L2 and L4 were cut. Microsequencing yielded the expected $\mathbf{N H}_{2}$-terminal sequence for $\mathrm{HuCha} 60$. The Coomassie blue staining intensity of HuCha 60 , relative to $\mathrm{L} 2$ and $\mathrm{L} 4$, indicated there was sufficient $\mathrm{L} 2$ and L4 for sequencing.

To obtain internal sequence information for $\mathrm{L} 2$ and $\mathrm{L} 4$, the Coomassie-stained protein spots ( 80 spots, $\sim 10 \mu \mathrm{g}$ ) of the same protein were pooled and digested in situ with trypsin. The gel pieces were incubated for $5 \mathrm{~h}$ at $37^{\circ} \mathrm{C}$ in $1 \mathrm{ml}$ of $100 \mathrm{mM} \mathrm{NH}_{4} \mathrm{HCO}_{3}, \mathrm{pH} 8.5,0.5$ $\mathrm{mM} \mathrm{CaCl}$, and $2 \mu \mathrm{g}$ trypsin (trypsin/protein ratio $\sim 1 \mu \mathrm{g}: 5 \mu \mathrm{g}$ ). The tryptic cleavage fragments were eluted from the polyacrylamide matrix with $1 \mathrm{ml}$ of $75 \%$ (vol/vol) trifluoroacetic acid in water and $1 \mathrm{ml}$ of $50 \%$ (vol/vol) trifluoroacetic acid in acetonitrile. The peptides were sepa- rated by reversed phase HPLC using a Vydac 201 TP 104 column (Anspec Co., Ann Arbor, MI). The eluent system was $0.1 \%$ (vol/vol) trifluoroacetic acid in double distilled water (solvent $A$ ) and $0.1 \%$ (vol/vol) trifluoroacetic acid in acetonitrile (solvent B). A gradient system of 0 to $60 \%$ solvent $B$ was run in $90 \mathrm{~min}$. The sequences of the collected peptides were then determined.

Quantification of L2 and L4. Each gel was scanned in a 1,024 $\times 1,024$ pixel format, giving $160 \mu \mathrm{m}$ as the pixel width. Spot detection and quantitation were performed using software from BioImage Corp. (Ann Arbor, MI). For the group of 150 patients with acute leukemia, the digitized gel images were assigned coded numbers and were analyzed for the presence and quantity of $\mathrm{L} 2$ and $\mathrm{L} 4$ without knowledge of the patient to whom a gel image corresponded or of the immunologic or other phenotypic traits of the leukemic cells. L2 and L4 were identified on the basis of their migration to positions in the gel determined by their pI and molecular weight. The positions of L2 and L4 were unique relative to constellations of neighboring landmark spots that were present in all gels included in this study and that were recognizable to the analyst. The $\mathrm{L} 2$ and $\mathrm{L} 4$ spots, as well as 20 other reference spots, were quantified by placing a cursor on each spot on the graphics monitor and typing in the name for the spot. The integrated intensity of each spot was measured in units of optical density times square millimeter. Data on these spots was transferred to an IBM 4361 running the Michigan Terminal System (MTS) operating system, in order to analyze data using the Michigan Interactive Data Analysis System (MIDAS), a statistical software package. The 20 reference spots were used to adjust the $\mathrm{L} 2$ and $\mathrm{L} 4$ spot-integrated intensities as previously described (4). For the most part, gels exhibiting L2 and L4 spots that were readily detectable by visual inspection of the gel yielded an integrated intensity that was $>0.4 \mathrm{OD} \times \mathrm{mm}^{2}$. Therefore, this value was chosen as a cutoff for categorizing cases with absence of L2 or L4. Gels exhibiting L2 were divided into three groups, based on the integrated intensity of L2: small (0.4-1.0), medium (1.0-2.0), and large $(\geq 2.0)$, as was previously done for L4 (4).

For comparisons of spot-integrated intensities between groups the rank-based Kruskal-Wallis statistic was used rather than parametric tests (ANOVA) that require the assumption of Gaussian distributions. For the same reason the rank-based correlation statistic known as Spearman's $\rho$ was used instead of the usual correlation coefficient (14).

\section{Results}

Occurrence of polypeptide $L 2$ in relation to cell type. The polypeptide pattern of leukemic cells from a patient with CALL is shown in Fig. 1. Most of the polypeptides observed in gels belonging to one subtype of ALL were also detected in the other subtypes, as well as in the nonleukemic lymphoid populations analyzed. However, as previously observed for L4 (4), the occurrence of L2 was closely associated with non-T ALL (Table I). Of 17 patients with T ALL only one exhibited the polypeptide $\mathrm{L} 2$ spot which was faint. Of 12 patients with acute myelogenous leukemia (AML), 10 lacked L2, 1 had a small amount of L2, and 1 was in the medium category. In contrast to other patients with AML, cells from the two patients that exhibited L2 expressed both HLA D/DR and TdT.

While polypeptide L2 was observed in B ALL and non-T ALL subtypes included in the study, it occurred in greatest abundance in cALL. The difference observed in the amount of L2 between CALLA-positive and CALLA-negative non-T ALL was statistically significant ( $P=0.03$, Kruskal-Wallis). Among the cALL group, only 3 of 98 patients were in the L2-negative category and half had a large L2. Among CALLA-negative patients, 6 of 20 lacked L2 and only 5 had a large L2. The six patients who lacked L2 were HLA D/DR positive and expressed the B cell marker CD19 (B4). 


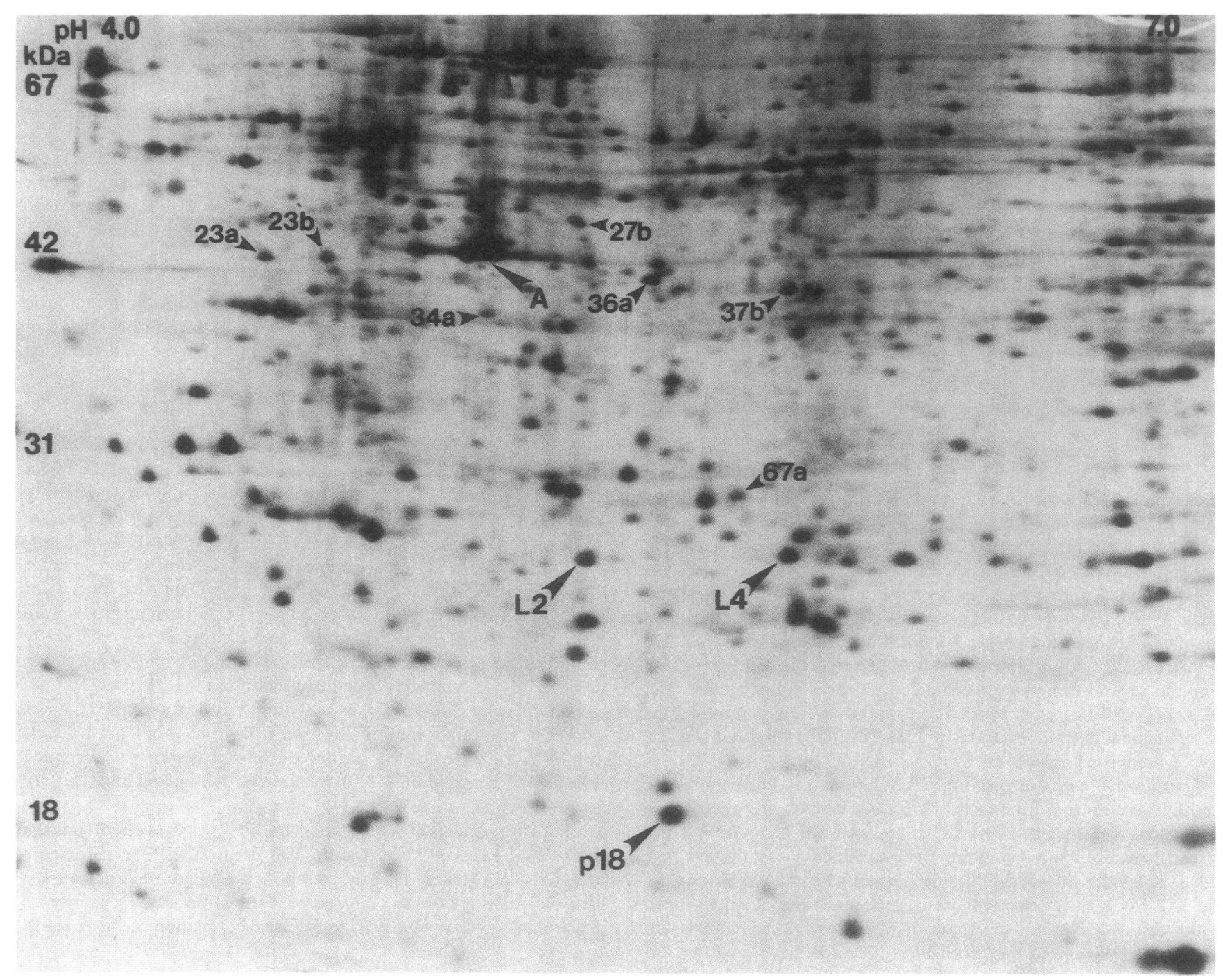

Figure 1. 2-D pattern of lymphoblast polypeptides from a patient with cALL exhibiting polypeptides L2 and L4. Spots labeled with small arrows identify polymorphic polypeptides ( $a$ and $b$ refer to the acidic and basic allele, respectively) previously identified in normal lymphocytes (15). Also indicated by large arrows are, actin $(A)$ and $\mathrm{p} 18$, a polypeptide associated with the malignant phenotype in acute leukemia (16). The $\mathrm{pH}$ is shown at the top and molecular mass on the left.

CD19 marker data were available for 18 CALLA-negative and 83 CALLA-positive non-T ALL patients. All patients expressed CD19 based on percentage of $\mathrm{CD} 19$ positive cells and intensity of fluorescence. CD20 (B1) marker data were available for 8 of the CALLA negative and 80 of the CALLA posi-

Table I. Occurrence of L2 in Relation to Subtype of Leukemia

\begin{tabular}{lrrrrrrr}
\hline & & \multicolumn{4}{c}{ L2 score } & \\
\cline { 3 - 6 } \multicolumn{1}{c}{ Diagnosis } & Total & Negative & Small & Medium & Large & $\begin{array}{c}\text { Mean spot } \\
\text { size }\end{array}$ \\
\hline AML & 12 & 10 & 1 & 1 & 0 & 0.33 \\
B ALL & 3 & 1 & 1 & 1 & 0 & 0.65 \\
CALLA + non-T ALL & 98 & 3 & 17 & 29 & 49 & 2.09 \\
CALLA - non-T ALL & 20 & 6 & 4 & 5 & 5 & 1.52 \\
T ALL & 17 & 16 & 1 & 0 & 0 & 0.07 \\
& & & & & & \\
\hline
\end{tabular}

$n=150$. tive non-T ALL patients. All of the CALLA negative patients were also CD20 negative. One was L2 negative and seven had moderate or large L2. For the CALLA-positive non-T ALL group (Table II), 63 patients had $<20 \%$ positive CD20 cells. The majority of these patients had moderate or large L2. Of

Table II. Abundance of L2 in CALL in Relation to Percentage of Blast Cells Expressing CD20 (B1)

\begin{tabular}{lccc} 
& \multicolumn{2}{c}{ CD20 } & \\
\cline { 2 - 3 } L2 score & $<20 \%$ & $>20 \%$ & Total \\
\hline Negative & 3 & 0 & 3 \\
Small & 8 & 7 & 15 \\
Medium & 14 & 6 & 20 \\
Large & 38 & 4 & 42 \\
Total & 63 & 17 & 80 \\
\hline
\end{tabular}


the 17 patients having $>20 \%$ positive CD20, all expressed $\mathrm{L} 2$. However, for the cALL group there was a significant difference in abundance of $\mathrm{L} 2$ with $\mathrm{CD} 20(P=0.01$ for the maximum likelihood test of independence in Table II).

Analysis of silver-stained 2-D patterns from sources other than ALL revealed absence of $L 2$ in normal peripheral blood $B$ and $T$ lymphocytes, lymphocytes isolated from thymus tissue, T cell clones, PHA-transformed T cells, EBV-transformed B cells, CLL, neutrophils, monocytes, and platelets. Among the cell lines studied, a spot in the position of L2 occurred in five of seven neuroblastoma cell lines, a pre-B leukemia cell line 697 that expresses CALLA (17) and a lymphoid cell line that expresses HLA D/DR and CD19 that was prepared from a patient with Bloom syndrome.

Occurrence of polypeptide $L 2$ in relation to polypeptide L4. The relative amounts of $\mathrm{L} 2$ and $\mathrm{L} 4$ among leukemia samples were highly correlated $(\rho=0.86, P=0.0001)$. The average integrated intensity of L2 in the non-T samples (1.99 \pm 1.24$)$ was higher than that for L4 $(1.55 \pm 1.16)$. The rank correlation coefficient between L2 and L4 for the CALLA positive non-T ALL group was $\rho=0.73, P<0.0001(n=98)$, and for the CALLA negative group was $\rho=0.79, P=0.0005(n=20)$. Within the CALLA-positive non-T ALL group, two patients that lacked polypeptide $\mathrm{L} 2$ also lacked polypeptide $\mathrm{L} 4$ and one lacked polypeptide L2 but exhibited a faint polypeptide L4 (integrated intensity $=0.50$ ). Alternatively, eight patients that lacked polypeptide L4 exhibited a faint polypeptide L2 with a mean integrated intensity of 0.64 . Within the CALLA-negative non-T ALL group, of the six patients that lacked polypeptide L2, four also lacked polypeptide L4 and two exhibited polypeptide $\mathrm{L} 4$ with integrated intensities of 0.66 and 0.95 . In this group, three patients lacked polypeptide L4 and had a moderately intense polypeptide $\mathrm{L} 2$.

Identification of L2 and L4 as heat shock proteins. Structural studies were undertaken to determine if L2 and L4 were related and if they represented polypeptides that were previously characterized. Proteins from a patient with CALL were separated by semipreparative 2-D PAGE and analyzed by gasphase amino acid microsequencing. No $\mathrm{NH}_{2}$-terminal sequences could be obtained for L 2 and $\mathrm{L} 4$ although a known polypeptide $\mathrm{HuCha} 60$, that was processed for sequencing similar to $\mathrm{L} 2$ and $\mathrm{L} 4$ yielded its expected $\mathrm{NH}_{2}$-terminal sequence. These results suggest that $\mathrm{L} 2$ and $\mathrm{L} 4$ are $\mathrm{NH}_{2}$-terminally blocked in vivo.

To obtain internal amino acid sequences, L2 and L4 were digested with trypsin and tryptic peptides were separated by reverse-phase HPLC. The HPLC tryptic peptide maps of L2 and L4 were essentially identical. Several peptides were selected for sequence determination. Fig. 2 shows the sequences obtained for four peptides from L4 (L4-A, -B, -C, and -D) and three peptides from L2 (L2-B, -C1, and -D). No sequence differences were found between any of the analyzed peptides of L2 and L4. The only qualitative difference between the HPLC tryptic maps was the presence of a peptide (L2-C1) in L2 not seen in L4. This peptide yielded a sequence that was identical to the first 9 residues of peptide L4-C and therefore resulted from acidic cleavage of the asp-pro bond in peptide C. A search of the sequence database of the Protein Identification Resource $^{2}(18)$ identified L2 and L4 as the human 27-kD heat

2. NBRF-PIR Protein Sequence Database. Supported by the Division of Research Resources of the NIH. Release 16.0, 31 March 1988. shock protein (hsp27), the gene for which had been cloned previously (5). Fig. 2 shows the corresponding amino acid sequences predicted from the human genomic clone 2711 for hsp27. The sequence of peptide A agrees with that predicted for positions 5-11 except for isoleucine at position 10 instead of leucine. Peptides B, C and D agree exactly with those predicted for residues $97-112,141-153$, and 172-188, respectively.

Response of L2 and L4 to heat shock. To determine if L2 and L4 expression in cALL and in lymphoid cells not normally expressing $\mathrm{L} 2$ and $\mathrm{L} 4$ could be increased or induced, as expected for heat shock proteins, various lymphoid cell populations were subjected to heat shock and their polypeptide pattern analyzed (Table III). After a 2-h heat shock exposure, cells were returned to $37^{\circ} \mathrm{C}$ to allow newly synthesized protein to accumulate. Fig. 3 shows a typical response to hyperthermia of a $\mathrm{T}$ cell clone which does not express $\mathrm{L} 2$ and $\mathrm{L} 4$ at $37^{\circ} \mathrm{C}$. After a period of $16 \mathrm{~h}$ after heat shock, there was a significant amount of L2 and L4 well above the detection threshold. Table III shows the results of L2 and L4 expression in response to heat shock for four $T$ cell clones not expressing $\mathrm{L} 2$ and $\mathrm{L} 4$, for cALL lymphoid cells and for a nonleukemic B lymphoblastoid cell line. Both L2 and L4 became detectable or increased in response to the heat shock treatment in all samples analyzed. Since there is a strong correlation between L2 and L4 and CALLA, an aliquot of control and heat-shocked cells was tested for CALLA. No change in the surface expression of CALLA was observed after heat shock in any of the sets of cells.

Labeling with ${ }^{32} P$. It is known that hsp27 is a phosphoprotein $(19,20)$. To ascertain the state of phosphorylation of L2 and L4, lymphoid cells from an EBV-transformed cell line expressing L2 and L4 were labeled in culture with inorganic $\left[{ }^{32} \mathrm{P}\right]$ phosphate. Silver stained 2-D gels were dried, marked with ink containing trace amounts of radioactivity for registration purposes, and autoradiograms prepared. L2 and L4 could be identified on the silver-stained gel (Fig. $4 \mathrm{~A}$ ) Autoradiography of the same gel revealed a number of phosphorylated polypeptides whose position on the autoradiograph (arrows, Fig. 4 $B$ ) unambiguously coincided with spots on the dried, silverstained gel (arrows, Fig. $4 \mathrm{~A}$ ). A phosphoprotein with a similar molecular weight of hsp27 was identified as L2 by overlaying the autoradiogram on the silver stained gel. No ${ }^{32} \mathrm{P}$ was detected in the position of L4. After heat shock, there was about a twofold increase in the amount of radioactivity associated with the L2 spot and none associated with L4 (data not shown). When normal peripheral blood lymphocytes, which do not express L2 or L4 as visualized by silver staining, were labeled with ${ }^{32} \mathrm{P}_{\mathrm{i}}$, a faint phosphoprotein was observed in the position of L2 (Fig. $5 \mathrm{~A}$ ). As was seen for $\mathrm{L} 2$ visualized by silver staining (Fig. 3), heat shock treatment resulted in a large (about threeto four-fold) increase in the amount of radioactivity associated with the L2 spot and none associated with L4 (Fig. 5 B).

\section{Discussion}

Most of the known cellular markers of differentiation that are expressed in leukemia represent surface antigens. Our analysis of the polypeptide constituents of lymphoid cell populations has revealed a relatively large number of predominantly cytosolic polypeptides that are expressed in various subtypes of acute lymphoblastic leukemia (3). The data presented in this 


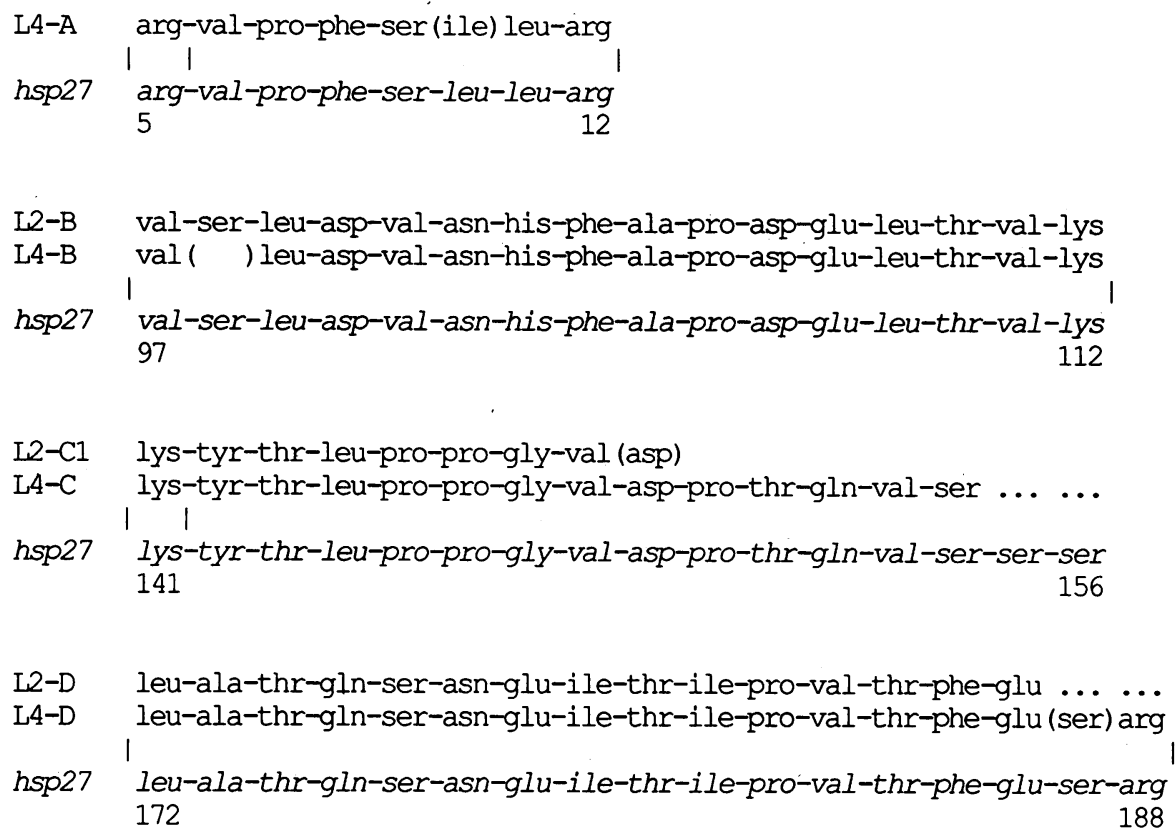

L2-C1 lys-tyr-thr-leu-pro-pro-gly-val (asp)

L4-C lys-tyr-thr-leu-pro-pro-gly-val-asp-pro-thr-gln-val-ser ... ... 11

hsp27 lys-tyr-thr-leu-pro-pro-gly-val-asp-pro-thr-gln-val-ser-ser-ser 141

L2-D leu-ala-thr-gln-ser-asn-glu-ile-thr-ile-pro-val-thr-phe-glu ... ...

L4-D leu-ala-thr-gln-ser-asn-glu-ile-thr-ile-pro-val-thr-phe-glu (ser) arg

hsp27 leu-ala-thr-gln-ser-asn-glu-ile-thr-ile-pro-val-thr-phe-glu-ser-arg 172

Figure 2. Amino acid sequences of selected L2 and L4 tryptic peptides. The amino acid sequence of three tryptic peptides of L2 (L2-B, - C1, and -D) and four peptides of L4 (L4-A, -B, -C, and -D) is shown. Residues within parentheses are tentative. Empty parentheses indicate no amino acid was identified at that cycle of Edman degradation. Dots indicate that the sequence could no longer be read. The relevant amino acid sequences predicted from the genomic DNA sequence of human 27-kD heat shock protein (5) are shown in italics. Vertical lines are predicted trypsin cleavage sites. The hsp27 peptide beginning at residue 141 is actually 31 residues long and only the first 16 amino acids are shown. Residue numbers refer to amino acids starting with the initiation codon and not to the actual processed hsp27. study establish the structural relatedness of two such polypeptides, designated $\mathrm{L} 2$ and $\mathrm{L} 4$, and their close association with the ALL subtype that is characterized in part by expression of CALLA and commitment for differentiation along a B cell pathway. The findings of identical HPLC tryptic maps for L2 and L4 and absence of amino acid differences between their corresponding peptides that were sequenced, together with the results of ${ }^{32} \mathrm{Pi}$ incorporation studies, allow us to conclude that L4 is a primary product of the hsp 27 mRNA, and L2 is a phosphorylated form of L4. Mammalian hsp27 has been shown to exist as unphosphorylated and phosphorylated forms that are encoded by at least one member of a four gene family $(5,19,20)$. Two of the genes have not been sequenced and the fourth is a pseudogene. The only instance of non-homology between the sequenced hsp 27 gene and L4 was the identification of isoleucine near the end of peptide L4. It is possible that L4 is encoded by one of the two unsequenced genes having an isoleucine at this position. Alternatively, this amino acid difference may represent a genetic polymorphism.

The identification of hsp 27 as a marker for cALL provides new insight into the differentiation program of lymphoid cells as can be derived from leukemia studies, as well as provides some additional clues as to the physiologic relevance of heat shock proteins. Our findings suggest a distinct pattern of regu-

Table III. Expression of L2 and L4 in Response to Heat Shock

\begin{tabular}{lccccc}
\hline & \multicolumn{4}{c}{ Integrated intensity* } \\
\cline { 2 - 3 } \cline { 5 - 6 } \cline { 5 - 6 } \multicolumn{1}{c}{ Cell type } & L2 & & \multicolumn{2}{c}{ L4 } \\
\cline { 2 - 3 } \cline { 5 - 6 } & Control & Heat shock & & Control & Heat shock \\
\hline $\begin{array}{l}\text { Average of 4 T cell clones } \\
\text { CALL Patient }\end{array}$ & 0.06 & 1.06 & & 0.35 & 2.22 \\
Nonleukemic & 0.89 & 4.59 & & 2.79 & 8.59 \\
$\quad$ Lymphoblastoid cell line & 1.07 & 3.50 & & 2.24 & 2.71
\end{tabular}

* Values $<0.4$ are categorized as negative in Table $I$. lation of hsp27 outside the heat shock response that is part of the B cell differentiation pathway. Nadler et al. (21) have delineated four subgroups of non-T ALL based on surface
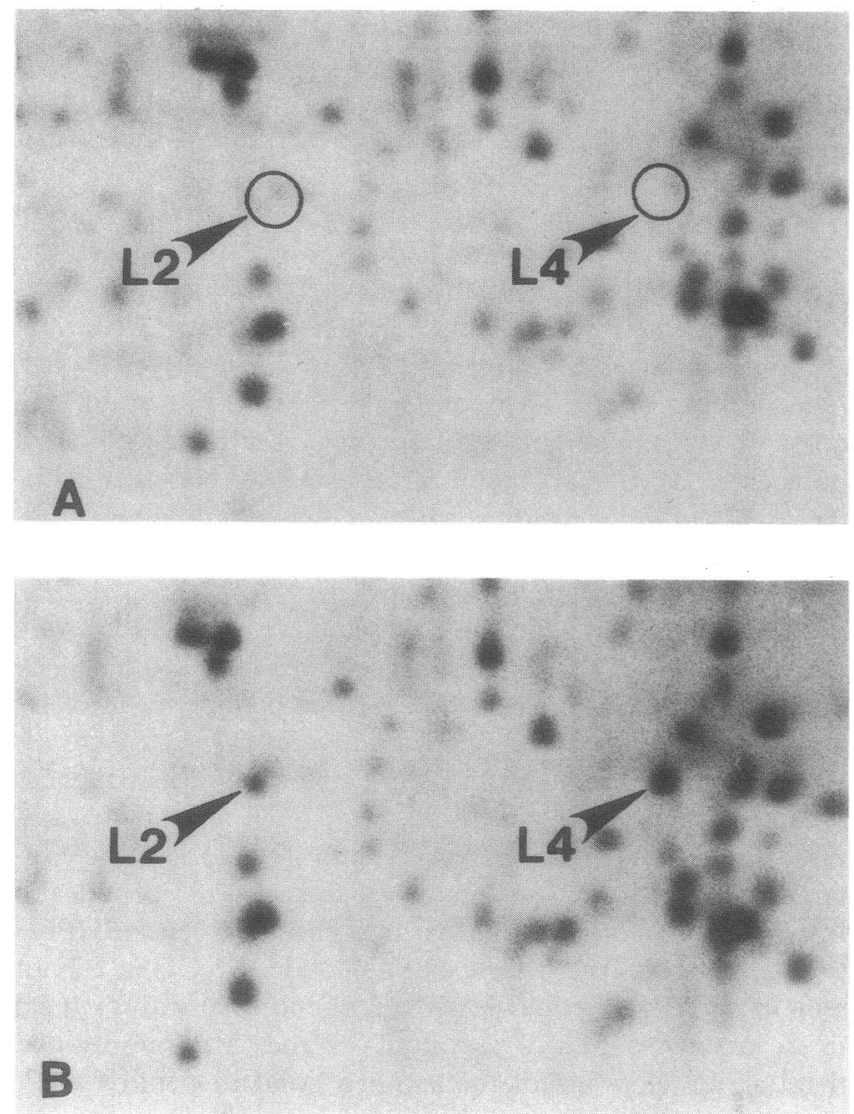

Figure 3. Close-up sections of 2-D gels of a control and a heatshocked nonleukemic T cell clone. (A) Control; (B) heat shock. A T cell clone was treated at $42^{\circ} \mathrm{C}$ for $2 \mathrm{~h}$ and returned to $37^{\circ} \mathrm{C}$ for $16 \mathrm{~h}$. Open circles indicate the absence of L2 and L4. 

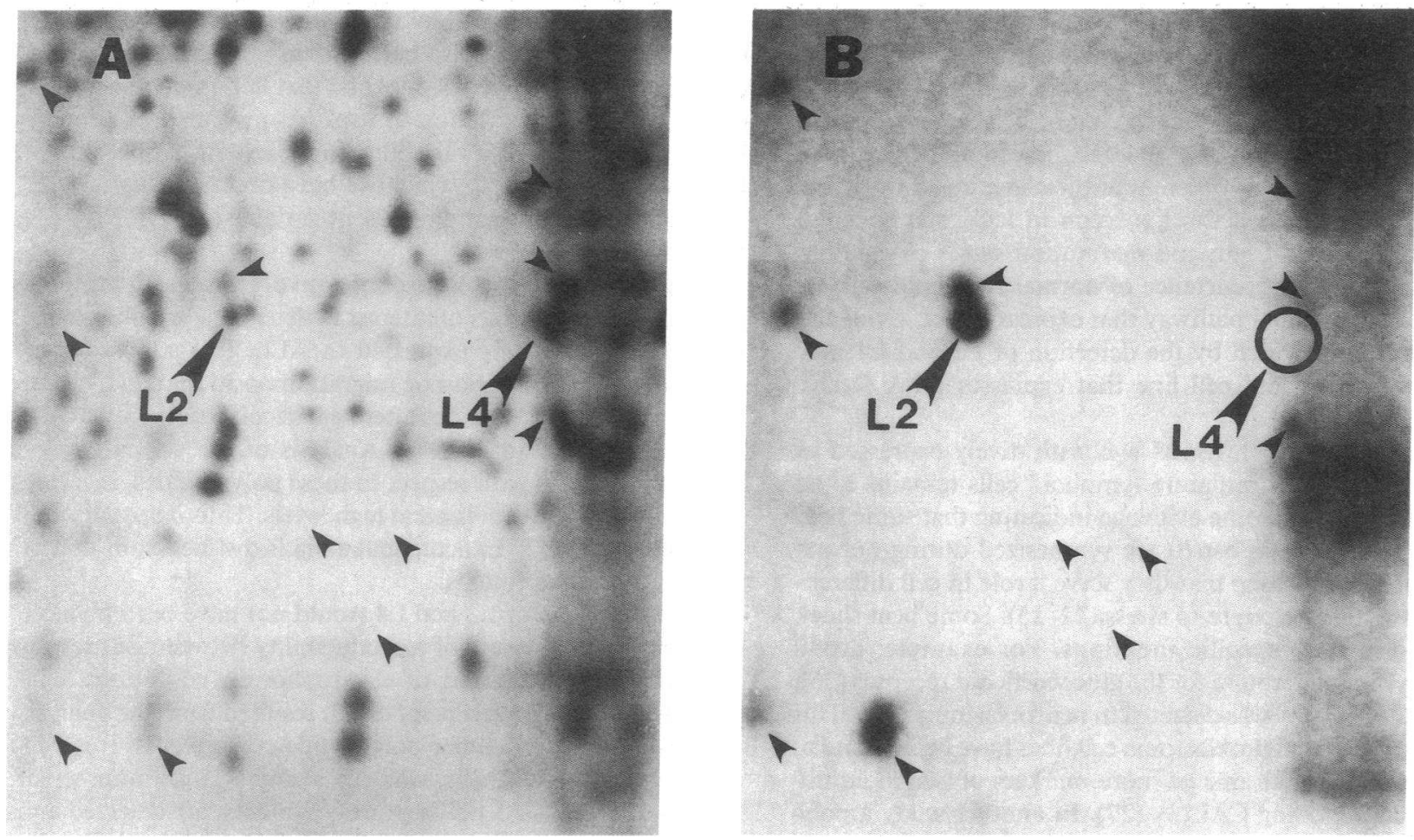

Figure 4. Identification of $\mathrm{L} 2$ as a phosphoprotein. Cells from a nonleukemic cell line established from a patient with Bloom syndrome which expresses both L2 and L4 were labeled in culture with ${ }^{32} \mathrm{P}_{\mathrm{i}}$. Cells in logarithmic growth in RPMI-1640 supplemented with $10 \%$ FCS were washed with phosphate-free media and incubated for $30 \mathrm{~min}$ at $37^{\circ} \mathrm{C} .{ }^{32} \mathrm{P}_{\mathrm{i}}$ was added $(250 \mu \mathrm{Ci} / \mathrm{ml})$ and cells were labeled for $16 \mathrm{~h}$. Polypeptides were separated by 2-D PAGE. After silver staining, the gel was dried and marked with ink containing trace amounts of radioactivity for registration purposes, and an autoradiograph prepared. $(A)$ A section of the silver-stained gel. $(B)$ Autoradiograph of the same gel section. Small arrows indicate phosphorylated polypeptides which were unambiguously identified by overlaying the autoradiograph on the dried, silver-stained gel. Large arrows indicate L2 and L4. The open circle shows the absence of radioactivity associated with L4 on the autoradiograph.

marker expression: HLA D/DR positive; HLA D/DR and B4 (CD19) positive; HLA D/DR, B4, and CALLA positive; and HLA D/DR, B4, CALLA, and B1 (CD20) positive. Whereas the HLA D/DR-only positive group is of uncertain lineage, strong evidence exists for progressive differentiation of the other three groups, along a B cell pathway. In our non-T ALL database, we have not observed any cases with L2 and L4 being expressed in the absence of the surface marker B4, indicating that hsp27 is expressed subsequent to B4 expression. Although there is a strong correlation between L2 and L4 and CALLA, several cases that were $\mathrm{B} 4$ positive and CALLA negative did express L2 and L4. Thus, in the non-T ALL subclassi-
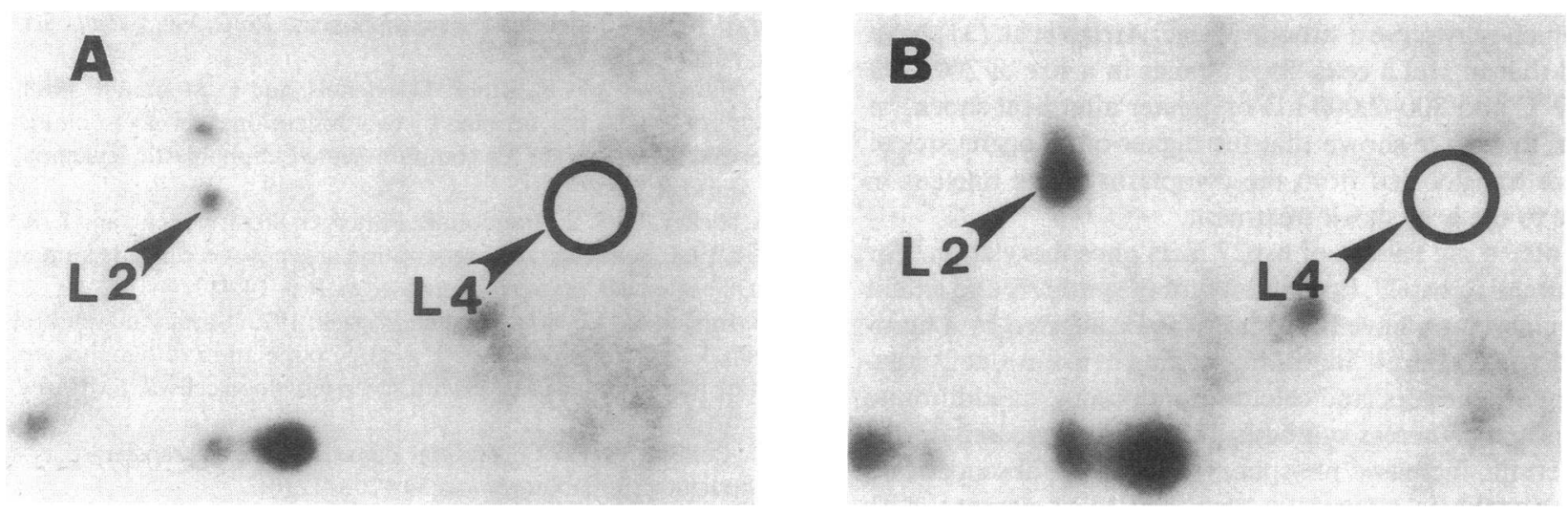

Figure 5. Autoradiography of normal peripheral blood lymphocyte phosphoproteins in response to heat shock. Normal peripheral blood lymphocytes were suspended in RPMI- 1640 supplemented with $10 \%$ FCS overnight. Cells were either held at $37^{\circ} \mathrm{C}$ or heat shock-treated at $42^{\circ} \mathrm{C}$ for $2 \mathrm{~h}$ and returned to $37^{\circ} \mathrm{C}$. Cells were then washed with phosphate-free media and incubated for $30 \mathrm{~min} .{ }^{32} \mathrm{P}_{\mathrm{i}}$ was added and cells were labeled for $18 \mathrm{~h}$ at $37^{\circ} \mathrm{C}$. $(A)$ Control; $(B)$ heat shock. Open circles indicate the absence of radioactivity associated with L4. 
fication scheme of Nadler et al. (21), the B4-positive/CALLAnegative class can be further subdivided based on L2/L4 expresssion. Since almost all the patients in the B4-positive/ CALLA-positive class, expressed L2 and L4, we conclude that L2/L4 expression occurs after B4 and precedes CALLA and spans the CALL stage of differentiation. Since most evidence indicates that selective gene expression in leukemia is determined by lineage of origin and maturation status of the cells (1), we postulate the occurrence of normal lymphoid cells in the B cell maturational pathway that express hsp27. Evidence to this effect is provided by the detection of L2 and L4 in a nonleukemic lymphoid cell line that expresses HLA D/DR and CD19.

The extent to which hsp27 is constitutively expressed in cell types other than immature lymphoid cells remains to be determined. There is some evidence indicating that some heat shock proteins such as hsp70 are synthesized during normal development, suggesting that they serve a role in cell differentiation, as well as response to stress (22-25). Some heat shock proteins also have specific functions. For example, hsp90 serves as a binding protein for the glucocorticoid receptor (26). In our studies, hsp27 was detected in neuroblastoma cells. This is of interest, since neuroblastoma cell lines have been found to exhibit reactivity with one or more markers of lymphoid differentiation including CALLA (27). In another study a polypeptide with similar characteristics as hsp27 was detected in human mammary carcinoma cells (28). Thus it is possible that hsp27 is generally expressed in a large number of immature cell types at a specific stage of differentiation.

Although the specific functions of hsp27 and most heat shock proteins are not known, in view of the evidence that these proteins have been highly conserved through evolution, it is likely that they play an important role. There is a high degree of homology between the hsp 27 and $\alpha$-crystallin, a lens protein. In Drosophila, four low molecular mass heat shock proteins $(22,23,26$, and $27 \mathrm{kD})$ exhibit a high degree of homology. In a region of homology with $\alpha$-crystallin near the $\mathrm{COOH}$-terminal end, the same amino acid as $\alpha$-crystallin is used by three of the heat shock proteins at 39 of 76 positions and by at least one heat shock protein at 53 of 76 positions (29). Since $\alpha$-crystallin is a highly specific polymeric protein, forming aggregates with average molecular mass of $800 \mathrm{kD}$ (30), this conserved $\mathrm{COOH}$-terminal domain may function in protein aggregation. Aggregates of hsp27 form in the cytoplasm which may serve a structural role. Arrigo et al. (31) have reported that in HeLa cells, hsp27 exists in a size of 200-800 $\mathrm{kD}$ at $37^{\circ} \mathrm{C}$ and $800-2,000 \mathrm{kD}$ or greater after heat shock. In addition, they have shown that the higher-order aggregates of hsp27 are translocated from the cytoplasm to the nucleus in response to the heat shock treatment.

An interesting feature of hsp27 is its phosphorylation. For the mammalian hsp27, both induction of synthesis and extent of phosphorylation have been shown to be affected by a number of diverse stimuli including arsenite, amino acid analogues, phorbol esters, and calcium ionophores, in addition to hyperthermia. Whereas synthesis of hsp27 is increased during hyperthermia, increased phosphorylation in the absence of increased synthesis occurs in response to treatment with phorbo-12-myristate-13-acetate, calcium ionophore, or stimulation of quiescent rat embryo fibroblast cells with fresh medium (19). The degree of phosphorylation varied in response to different stimuli, suggesting that phosphorylation may be the means by which the biological activity of these polypeptides is regulated. It has also been shown that phosphorylation of hsp 27 involves serine residues and that in human mammary carcinoma, phosphorylation of hsp27 is mediated by protein kinase $C(28)$. Thus the variability in the extent of phosphorylation of hsp27 in cALL which we have observed might be of biological significance and represent variable expression or activity of protein kinase $C$.

Since the heat shock response involves several proteins other than hsp27, it was of interest to determine whether other hsps are constitutively expressed in ALL. It was possible to determine the electrophoretic migration position of two hsp70 and two hsp 80 polypeptides after heat shock treatment of lymphoid cells (data not shown). Analysis of the gel pattern of leukemia samples with respect to these polypeptides, revealed that they were not expressed at high levels. Thus it appears that expression of hsp27 in acute leukemia is distinct from that of other heat shock proteins.

The detection of L2 and L4 would not have been possible without a high measure of reproducibility between gels resulting from standardization of electrophoretic conditions. The detection of these markers for cALL resulted from the analysis of only $\mathbf{4 0 0}$ of the cellular polypeptide constituents. It is currently possible to reliably analyze a much larger number of polypeptides (32). As polypeptides of interest are detected and sequenced and their genes are cloned, it should be possible to substantially improve the characterization of leukemic and other cancer cells with respect to their lineage, stage of differentiation, and extent of metabolic alterations.

\section{Acknowledgments}

This work was supported by grants CA-26803, CA-32146, and HL-16008 from the U. S. Public Health Service.

\section{References}

1. Greaves, M. F. 1986. Differentiation-linked leukemogenesis in lymphocytes. Science (Wash. DC). 234:697-704.

2. Crist, W. M., C. E. Grossi, and D. J. Pullen. 1985. Immunologic markers in childhood acute lymphocytic leukemia. Sem. Oncol. 12:105-121.

3. Hanash, S. M., L. J. Baier, L. McCurry, and S. Schwartz. 1986. Lineage related polypeptide markers in acute lymphoblastic leukemia detected by two-dimensional electrophoresis. Proc. Natl. Acad. Sci. USA. 83:807-811.

4. Hanash, S. M., R. Kuick, D. Nichols, and L. Stoolman. 1988. Analysis of cellular polypeptides by two-dimensional gel electrophoresis reveals a new marker for common acute lymphoblastic leukemia. Dis. Markers. 6:209-220.

5. Hickey, E., S. E. Brandon, R. Potter, G. Stein, J. Stein, and L. A. Weber. 1986. Sequence and organization of genes encoding the human 27 kDa heat shock protein. Nucleic Acids Res. 14:4127-4145.

6. Jondal, M., G. Holm, and H. Wigzell. 1972. Surface markers on human $\mathrm{T}$ and B lymphocytes. I. A large population of lymphocytes forming non-immune rosettes with sheep red blood cells. J. Exp. Med. 136:207-214.

7. Bollum, F. 1979. Terminal deoxynucleotidyl transferase as a hemopoietic cell marker. Blood. 54:1203-1210.

8. Hanson, C. A., and K. J. Gajl-Peczalska. 1988. Monoclonal antibodies to lymphoreticular and myeloid antigens. In Diagnostic Use of Monoclonal Antibodies in Clinical Immunohistochemistry. M. R. Wick and G. P. Segal, editors. Marcel Decker, Inc., New York. 147-226. 
9. Higgs, J. B., W. Zeldes, K. Kozarsky, M. Schteingart, L. Kan, P. Bohlke, K. Kreiger, W. Davis, and D. A. Fox. 1988. A novel pathway of human $\mathrm{T}$ lymphocyte activation. Identification by a monoclonal antibody generated against a rheumatoid synovial T cell line. J. Immunol. 140:3758-3765.

10. Strahler, J. R., R. Kuick, and S. M. Hanash. 1989. Two-dimensional polyacrylamide gel electrophoresis of proteins. In Protein Structure: A Practical Approach. T. E. Creighton, editor. IRL Press, Oxford, England. 65-92.

11. Merril, C. R., D. Goldman, S. A. Sedman, and M. H. Ebert. 1981. Ultrasensitive stain for proteins in polyacrylamide gels show regional variation in cerebrospinal fluid. Science (Wash. DC). 211:1437-1438.

12. Eckerskorn, C., W. Mewes, H. Goretzki, and F. Lottspeich. 1988. A new siliconized-glass fiber as support for protein-chemical analysis of electroblotted proteins. Eur. J. Biochem. 176:509-519.

13. Waldinger, D., C. Eckerskorn, F. Lottspeich, and H. Cleve. 1988. Amino acid sequence homology of the polymorphic cellular protein from human lymphocytes and the chaperonins from $E$. col (Pro EL) and chloroplasts (rubisco binding protein). Biol. Chem. 369:1185-1189.

14. Lehmann, E. L. 1975. Nonparametrics. Holden-Day Inc., San Francisco.

15. Hanash, S. M., L. J. Baier, R. Kuick, M. Galteau, and D. Welch. 1986. Genetic variants detected among one hundred and six lymphocyte polypeptides observed in two-dimensional gels. Am. J. Hum. Genet. 39:317-328.

16. Hanash, S. M., J. R. Strahler, R. Kuick, E. H. Y. Chu, and D. Nichols. 1988. Identification of a polypeptide associated with the malignant phenotype in acute leukemia. J. Biol. Chem. 283:1281312815.

17. Green, R. J., H. W. Findley, A. T. L. Chen, and A. H. Ragab. 1982. Characterization of a new chromosomal marker for acute lymphoblastic leukemia from a long-term cell line. Cancer Genet. Cytogenet. 7:247-269.

18. George, D. G., W. C. Barker, and L. T. Hunt. 1986. The protein identification resource (PIR). Nucleic Acids Res. 14:11-15.

19. Welch, W. J. 1985. Phorbol ester, calcium ionophore, or serum added to quiescent rat embryo fibroblast cells all result in the elevated phosphorylation of two 28,000 -Dalton mammalian stress proteins. $J$. Biol. Chem. 260:3058-3062.

20. Kim, Y.-J., J. Shuman, M. Sette, and A. Przybyla. 1983. Phosphorylation pattern of a $25 \mathrm{kDalton}$ stress protein from rat myoblasts. Biochem. Biophys. Res. Commun. 117:682-687.
21. Nadler, L. M., S. J. Korsmeyer, K. C. Anderson, A. W. Boyd, B. Slaughenhoupt, E. Park, J. Jensen, F. Coral, R. J. Mayer, S. E. Sallan, J. Ritz, and S. F. Schlossman. 1984. B cell origin of non-T cell acute lymphoblastic leukemia: a model for discrete stages of neoplastic and normal pre-B cell differentiation. J. Clin. Invest. 74:332-339.

22. Bensaude, O., and M. Morange. 1983. Spontaneous high expression of heat-shock proteins in mouse embryonal carcinoma cells and ectoderm from day 8 mouse embryo. EMBO (Eur. Mol. Biol. Organ.) J. 2:173-177.

23. Bienz, M. 1984. Developmental control of the heat shock response in Xenopus. Proc. Natl. Acad. Sci. USA. 81:3138-3142.

24. Hahnel, A. C., D. J. Gifford, J. J. Heikkila, and G. A. Schultz. 1986. Expression of the major heat shock protein (hsp70) family during early mouse development. Teratog. Carcinog. Mutagen. 6:493510.

25. Kurtz, S., J. Rossi, L. Petko, and S. Lindquist. 1986. An ancient developmental induction: heat-shock proteins induced in sporulation and oogenesis. Science (Wash. DC). 231:1154-1156.

26. Howard, K. J., and C. W. Distelhorst. 1988. Evidence for intracellular association of the glucocorticoid receptor with the $90-\mathrm{kDa}$ heat shock protein. J. Biol. Chem. 263:3474-3481.

27. Sugimoto, T., E. Tatsumi, J. T. Kemshead, L. Helson, A. A. Green, and J. Minowada. 1984. Determination of cell surface membrane antigens common to both human neuroblastoma and leukemia-lymphoma cell lines by a panel of 38 monoclonal antibodies. $J$. Natl. Cancer Inst. 73:51-57.

28. Regazzi, R., U. Eppenberger, and D. Fabbro. 1988. The 27,000 Daltons stress proteins are phosphorylated by protein kinase-C during the tumor promoter-mediated growth-inhibition of human mammary-carcinoma cells. Biochem. Biophys. Res. Commun. 152:62-68.

29. Ingolia, T. D., and E. A. Craig. 1982. Four small Drosophila heat shock proteins are related to each other and to mammalian $\alpha$ crystallin. Proc. Natl. Acad. Sci. USA. 79:2360-2364.

30. Bloemendal, H., T. Berns, A. Zweers, H. Hoenders, and E. L. Benedetti. 1972. The state of aggregation of $\alpha$-crystallin detected after large-scale preparation by zonal centrifugation. Eur. J. Biochem. 24:401-406.

31. Arrigo, A.-P., J. P. Suhan, and W. J. Welch. 1988. Dynamic changes in the structure and intracellular locale of the mammalian low-molecular-weight heat shock protein. Mol. Cell. Biol. 8:50595071.

32. Strahler, J. R., S. M. Hanash, L. Somerlot, A. Gorg, J. Weser, and W. Postel. 1987. High resolution two-dimensional polyacrylamide gel electrophoresis of basic polypeptides: use of immobilized $\mathrm{pH}$ gradients in the first dimension. Electrophoresis. 8:165-173. 